\title{
EFFECT OF POSITIONAL INACCURACIES ON MULTIELECTRODE RESULTS
}

\author{
S Szalai ${ }^{1,2}$, A KoppáN $^{1}$, L Szarka $^{1,2}$ \\ ${ }^{1}$ Geodetic and Geophysical Research Institute of the Hungarian Academy of Sciences, \\ POB 5, H-9401 Sopron, Hungary, e-mail: szalai@ggki.hu, koppan@ggki.hu, szarka@ggki.hu \\ ${ }^{2}$ University of West-Hungary, Bajcsy-Zsilinszky u. 4, H-9400 Sopron, Hungary
}

[Manuscript received November 30, 2007; accepted January 9, 2008]

\begin{abstract}
This paper investigates the effect of electrode positioning errors on the inverted pseudosection. Instead of random spacing errors (as usually assumed in geoelectrics) we exactly measured this effect among field conditions. In the field, in spite of the greatest possible care, the electrode positions contain some inaccuracy: either in case of dense undergrowth, or varied topography, or very rocky field. In all these cases, it is not possible to put the electrodes in their theoretical position. As a consequence, the position data will contain some error. The inaccuracies were exactly determined by using a laser distance meter. The geometrical data from real field conditions and by using Wenner- $\alpha$, Wenner- $\beta$, pole-dipole and pole-pole arrays were then considered over homogeneous half space.

As we have found, the positioning errors can be regarded as insignificant, even in case of relatively uncomfortable field conditions. However, in case of very rocky surface the distortions are more significant, but it is still possible to make some corrections: either by neglecting a few electrode positions with the greatest positioning error, or to minimize the inline errors, even on the price that offline deviations are high.
\end{abstract}

Keywords: errors; geometrical factor; multielectrode (measurement); positional inaccuracies; surface rockiness 


\section{Introduction}

The multielectrode measurements are influenced by various errors. Realising the popularity of multielectrode measurements, and an oversimplification tendency in their handling (e.g. considering the errors as random noise), we have found as an actual task to investigate their consequences on the interpretation. From such an investigation we expect to find out the effect of various errors on the resulting data. Furthermore, some elimination possibilities of such errors are also expected.

One of the errors comes from the inaccurate positioning of the electrodes. In realistic field conditions, in spite of the greatest possible care, the electrode positions do contain some inaccuracy, thus it is not possible to put the electrodes in their theoretical position. As a consequence, the position data will be distorted. This effect has been taken into account as random. For example, Loke and Barker (1995) assumed Gaussian noise with an amplitude of 5\%, Zhou and Dahlin (2003) mentioned a random noise of $10 \%$ amplitude, Athanasiou et al. (2007) assumed a random noise of $3 \mathrm{mV} / \mathrm{A}$ peak-to-peak amplitude. Zhou and Dahlin (2003) found that $10 \%$ random spacing error may cause a more than $20 \%$ resultant effect on the inverted pseudosection.

This paper is the first publication, where the electrode positioning errors are precisely measured. In this paper we present, what pseudo-anomalies arise due to positioning errors of the electrodes. At first the method, then the results obtained in case of dense undergrowth and/or varied topography, then in case of high surface rockiness are presented.

\section{Method}

Multielectrode measurements were carried out along four measuring profiles, representing four different field conditions. P1 was an ideal (visibly free and horizontal) measuring line; P2 and P3 are characterised by less (P2) or more (P3) dense undergrowth and/or varied topography (see Fig. 2); P4 was nearly ideal from the point of view of undergrowth and topography, but its surface rockiness was very high (as shown in Fig. 3).

In the four different field conditions (undergrowth density, high-frequency topographic variation, surface rockiness) we set out the measuring profile, then we determined - by means of a laser distance meter - the exact $\mathbf{r}=\{x, y\}$ position of the electrodes. See Fig. 1, where $x$ is parallel to the profile ("inline"), $y$ is perpendicular to it ("offline"). Using the real position of the electrodes, we computed the corresponding apparent resistivity values on the surface of a hypothetic half-space of $100 \mathrm{ohmm}$, by applying the geometrical factor of the ideal situation. Then the computed apparent resistivity data were inverted. All these steps are steps of the normal procedure. The inversion was carried out by using the AGI Earth Imager $2 \mathrm{D}$ software. Such computations were carried out for Wenner- $\alpha$ (Wa), Wenner- $\beta$ $(\mathrm{Wb})$, pole-dipole (PDP) and pole-pole (PP) arrays, and a distance of $1 \mathrm{~m}$ was applied between the neighbouring electrodes. 


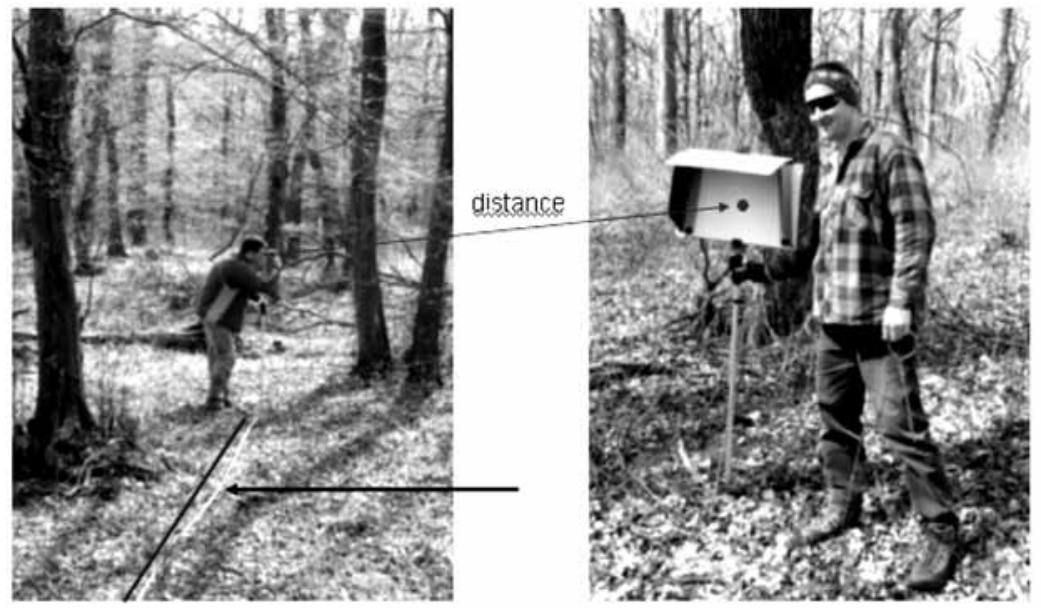

Fig. 1. Determination of the electrode positions by means of laser distance meter along the measuring line P2 (note the tortuosity of the tape-measure, due to the bumpy surface)

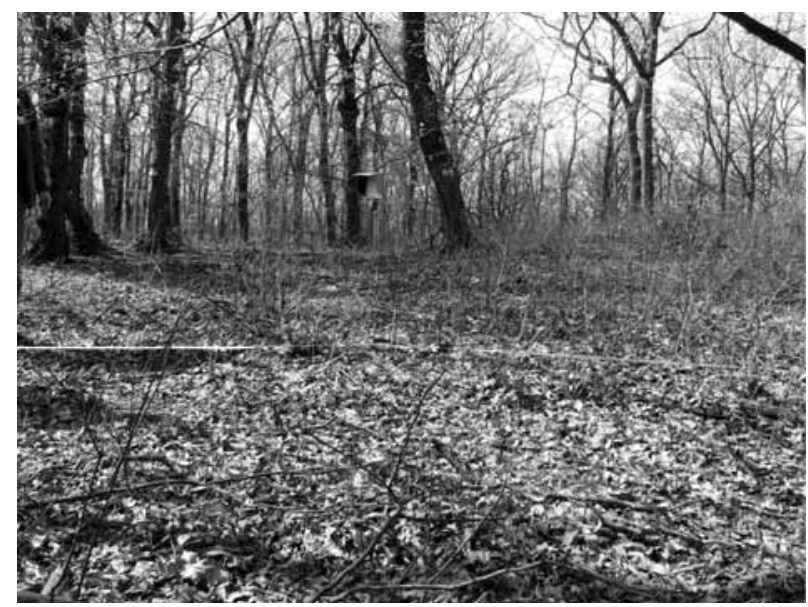

Fig. 2. P2 was measured in an area of less dense undergrowth (foreground), P3 was measured in the background

\section{Dense undergrowth and/or varied topography}

Where the rockiness was relatively low, the average of $\left|\mathbf{r}_{\text {ideal }}-\mathbf{r}_{\text {real }}\right|$ proved to be - quite surprisingly - only $12-13 \mathrm{~mm}$, that is only $1.2-1.3 \%$ of the electrode distance of $1 \mathrm{~m}$. The maximum error $\left(\left|r_{\text {ideal }}-r_{\text {real }}\right|_{\max }\right)$ was only $8 \mathrm{~cm}(8 \%)$. These geometric inaccuracies may lead to higher false anomalies than $10 \%$ in the nearsurface region, but they drastically diminish with depth, as it is shown in Fig. 4 for the four arrays. At the depth of $1 / 3$ part of the depth of investigation, the intensity of false anomalies becomes less than $2 \%$. (Larger values than $2 \%$ were obtained only in case of the Wenner- $\beta$ array.) 


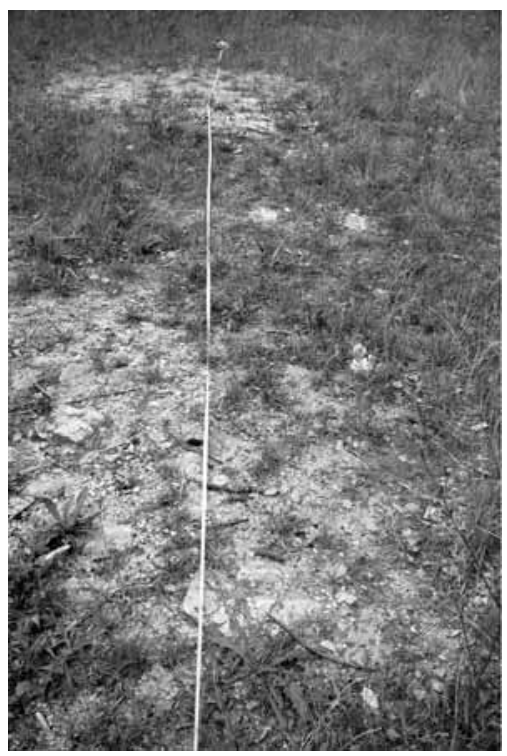

Fig. 3. P4, the rocky profile

Since the values of inaccuracies $(1.2-1.3 \mathrm{~cm}$ as average or $8 \mathrm{~cm}$ as maximum) remain the same in case of even larger electrode spacings than $1 \mathrm{~m}$, it is sure that dense undergrowth and/or varied topography cause less errors than usually assumed.

\section{Rocky surface}

In case of significant surface rockiness it is not possible to insert the electrodes into the soil over larger surface pieces. Instead of their correct position, it is only possible to put them into an evidently incorrect point (as it is illustrated in Fig. 6 with a $\Delta x$ and a $\Delta y$ value.) Consequently the false anomalies may become much more significant, as it is illustrated in Fig. 5 for the Wenner- $\alpha$ and Wenner- $\beta$ arrays.

In order to reduce this effect, we carried out systematic experiments along line P4. In the first experiment we tried to put the electrodes as close to their ideal position as possible. In spite of this effort, the positional inaccuracies in both $x$ (inline) and $y$ (offline) directions in case of 9 electrodes (among the 60 ones) proved to be higher than $10 \mathrm{~cm}(10 \%$, assuming an electrode distance of $1 \mathrm{~m})$. The inverted resistivity pseudosection (Fig. 7 a) indicates very false anomalies. One of them is seen with a centre at a distance of $30 \mathrm{~m}$ and at a depth of about $10 \mathrm{~m}$. This false anomaly could not be removed neither by ignoring even all those (four) electrodes where the positioning error $\left|x_{\text {ideal }}-x_{\text {real }}\right|$ was larger than $15 \mathrm{~cm}$ (Fig. $7 \mathrm{~b}$ ), nor by ignoring the four electrodes where $\left|y_{\text {ideal }}-y_{\text {real }}\right|>30 \mathrm{~cm}$ (not shown). Ignoring electrodes could be in theory a way to reduce such false anomalies, but ignoring so many (4 or $4+4)$ electrodes may already endanger the correct interpretation.

For this problem we have found an alternative solution as follows. When it is not 

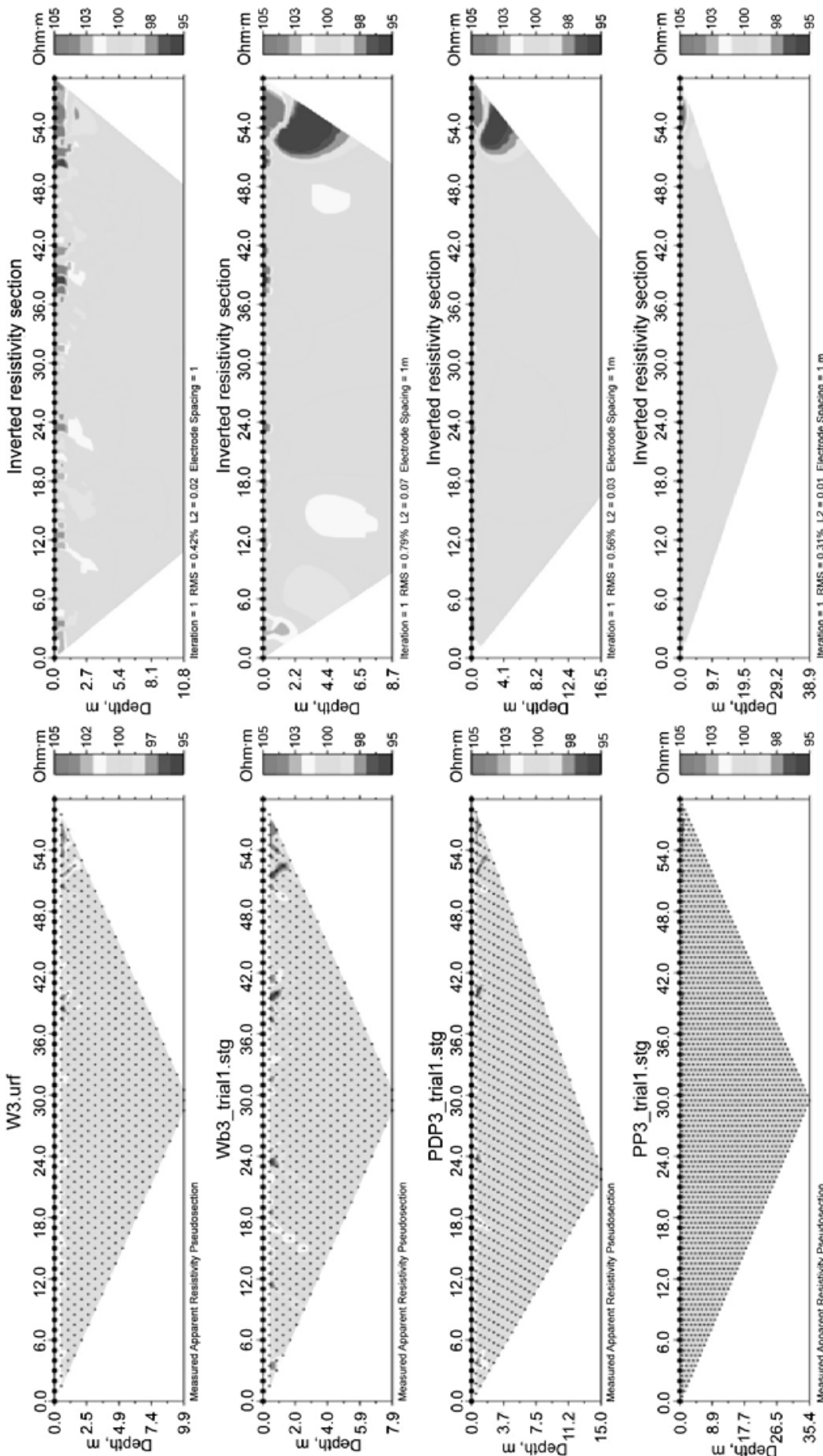

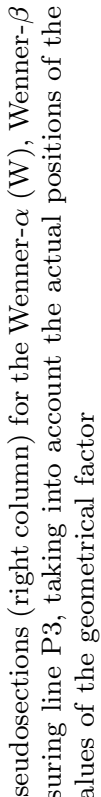
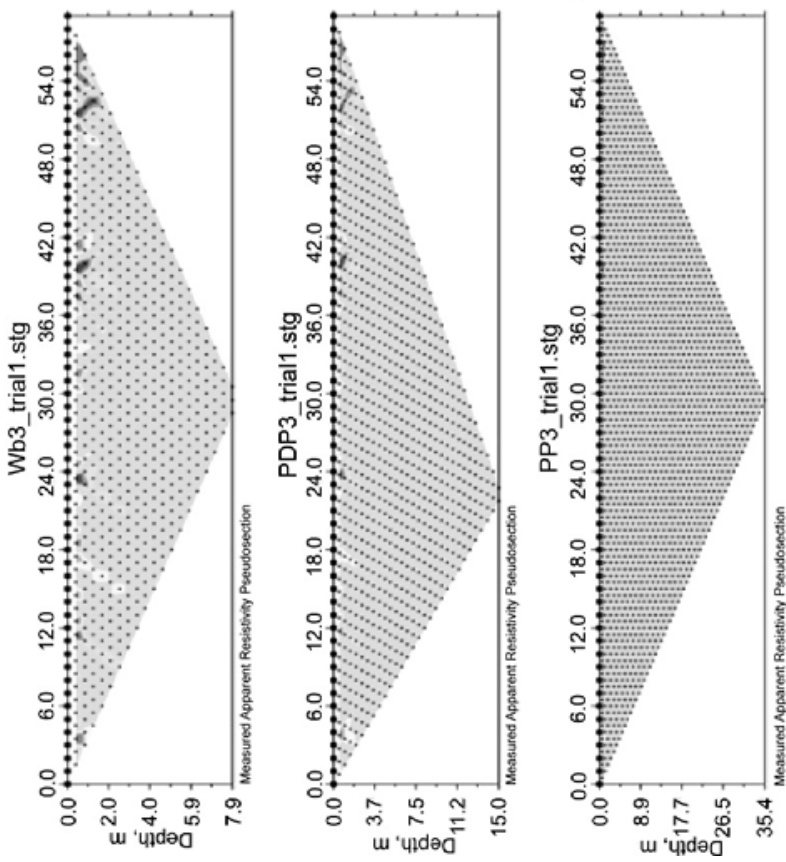

屯.

峞

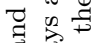

สี

응

过

幽

它

究的

包

평 웅

해

它定 

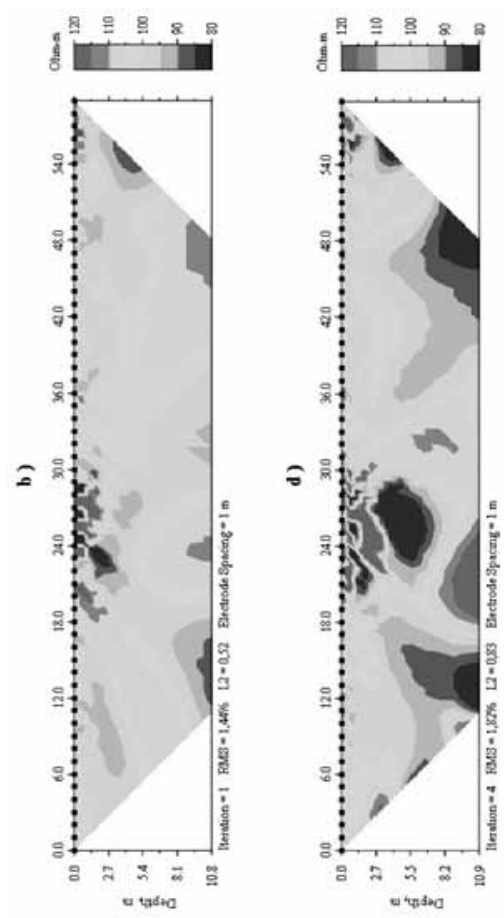

풍

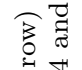

$\overrightarrow{0}$

을.

o

밀

है

正

के 운

ชิ

चี

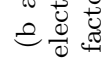

总 要焉

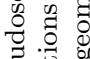
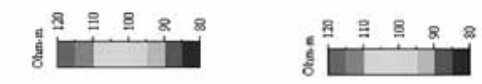

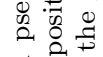
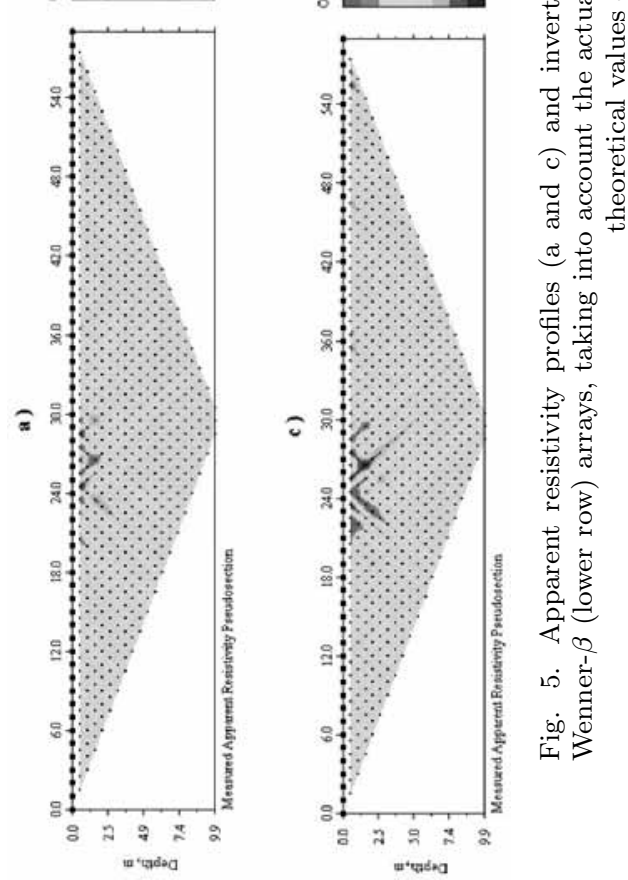

Acta Geod. Geoph. Hung. 43, 2008 


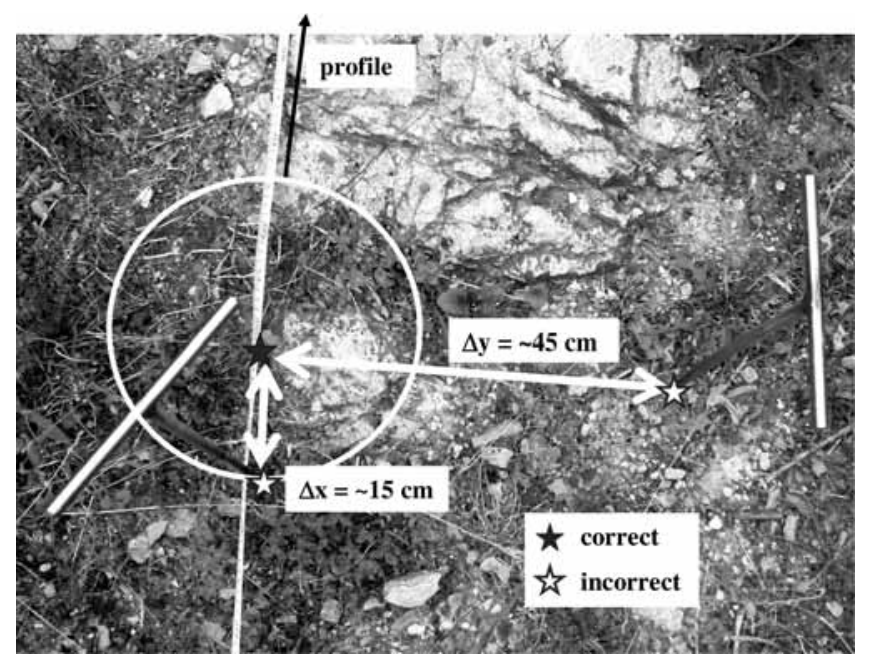

Fig. 6. Electrode mispositioning in $x$-, or $y$ direction on rocky surface

a)

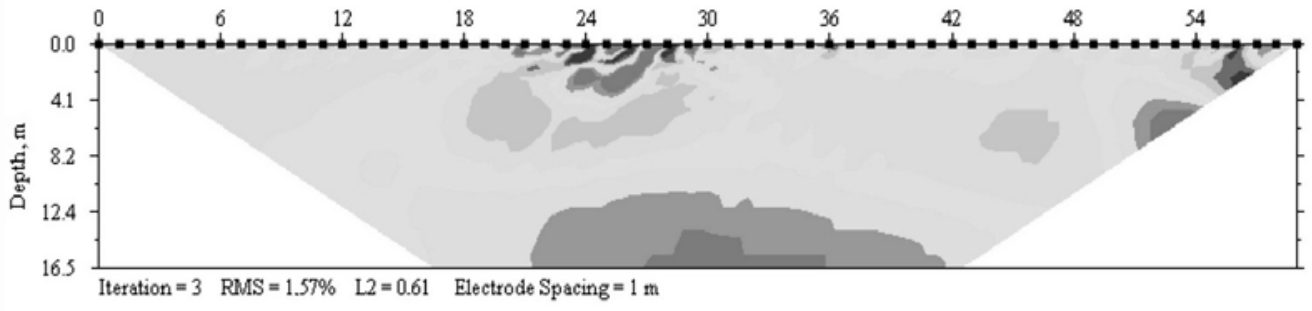

b)

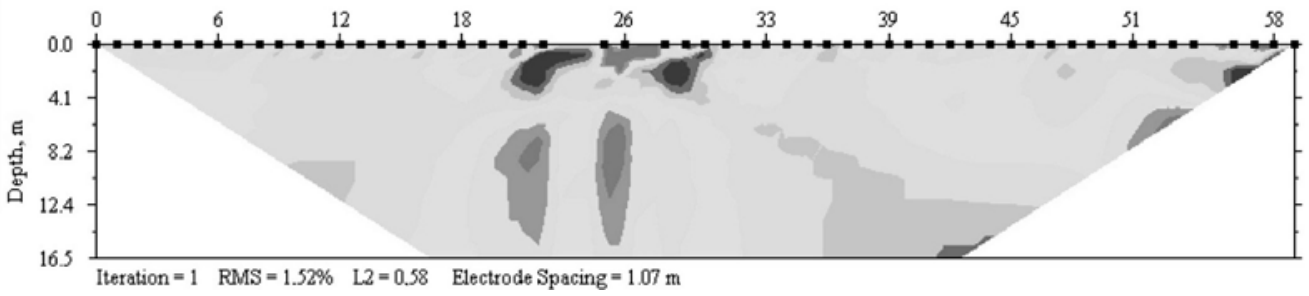

Fig. 7. Inverted resistivity pseudosection for the PDP array along profile P4, where $\left|\mathbf{r}_{\text {ideal }}-\mathbf{r}_{\text {real }}\right|$ was minimised. a) Considering all electrodes, b) removing four electrodes (23, 24, 27 and 55), where the positioning error in $\mathrm{x}$-direction was larger than $15 \mathrm{~cm}$

possible to put the electrodes in their theoretical position, we recommend to commit the positioning error rather in offline than in inline direction. In this case the false anomalies become less significant (both in their magnitude and extent), and remain important only in the near-surface region (except when the deviation is extremely big). When deviations are caused by only 1-2 electrodes, they can be easily ignored in the inversion procedure, without endangering the correct interpretation. 


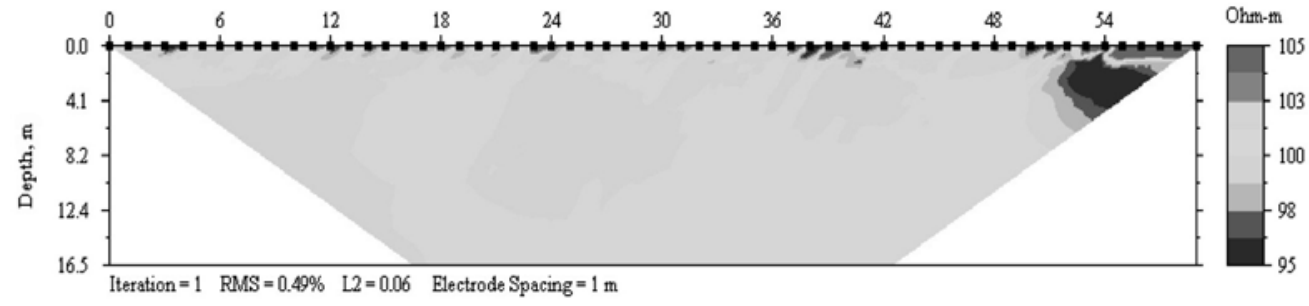

b)

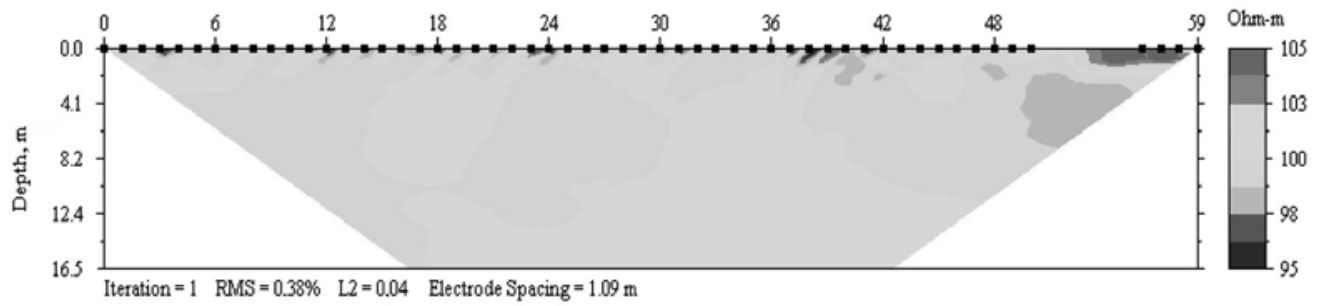

Fig. 8. Inverted resistivity pseudosection for the PDP array along line $\mathrm{P} 4$, where $\left|x_{\text {ideal }}-x_{\text {real }}\right|$ was minimised. a) Considering all electrodes, b) removing five electrodes (51-55), where $\left|x_{\text {ideal }}-x_{\text {real }}\right|>6 \mathrm{~cm}$

In Fig. $8\left|y_{\text {ideal }}-y_{\text {real }}\right|$ was higher than $20 \mathrm{~cm}$ for five electrodes (electrodes 40-44). Nevertheless a significant false anomaly appeared only at the end of the measuring line (electrodes 51-55), where the positioning errors arose in $x$ direction! Ignoring all those electrodes, where $\left|x_{\text {ideal }}-x_{\text {real }}\right|>7 \mathrm{~cm}$, the inverted pseudosection become less distorted (Fig. 8 b).

In Fig. 9 the histogram of inline- and offline positioning errors are shown. In line $\mathrm{P} 4$, where we tried to keep $\left|\mathbf{r}_{\text {ideal }}-\mathbf{r}_{\text {real }}\right|$ on a minimum level, similar histograms were obtained for $\mathrm{x}$ - and $\mathrm{y}$-directed errors. At the same time, where we tried to keep a minimum $\left|x_{\text {ideal }}-x_{\text {real }}\right|$, the $x$-directed positioning errors become of course much less, while the $y$-directed ones remain significant over a wide range.

\section{Conclusions}

In this study we investigated the consequences of positioning errors on the interpreted results, among real field conditions, where the co-ordinates of the electrodes differ from their theoretical ones. The actual positioning errors were determined by means of a laser distance meter, then the effects of positioning errors on the apparent resistivity- and inverted resistivity pseudosections were computed, assuming a homogeneous and isotropic half-space. Such computations were carried out for Wenner- $\alpha$ and $-\beta$, pole-dipole and pole-pole geoelectric arrays.

The positioning error proved to be relatively low among even very inconvenient field conditions, and they have influence first of all only to the near-surface data, which may not be so important in the interpretation. In case of high surface rocki- 
$\mathrm{x}$ errors, $\mathrm{cm}$
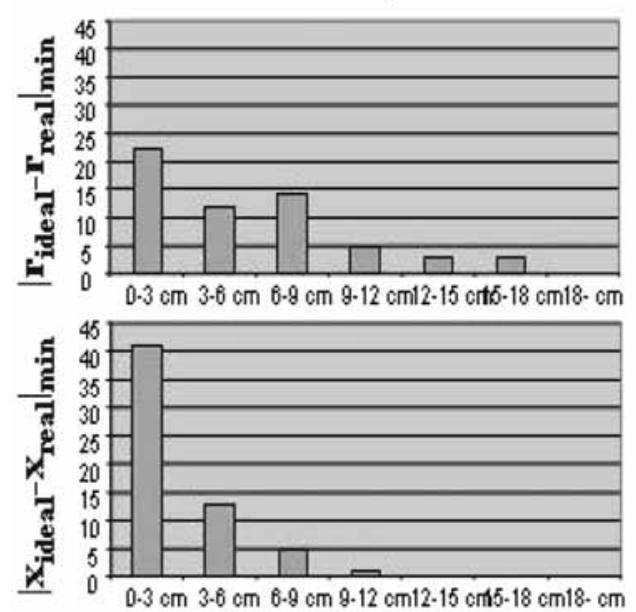

y errors, $\mathrm{cm}$

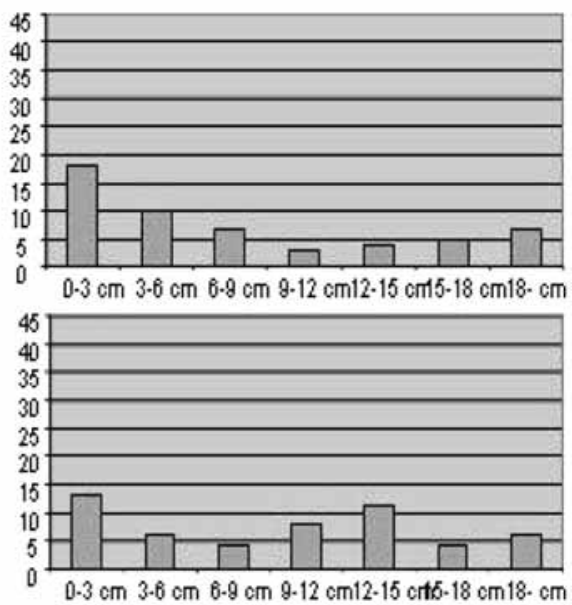

Fig. 9. Distribution of $x$ - and $y$-directed positioning errors ( $x$-directed errors: left, $y$-directed errors: right) along line $\mathrm{P} 4$

ness, where the rocks do not make possible an exact positioning of the electrodes, the consequences may be more significant. Anyway, the error in percentage is higher in case of small electrode spacings.

In order to be able to eliminate these problems, it is advisable 1. avoid areas where the surface rockiness is important (if it is possible at all), 2. try to keep $\left|x_{\text {ideal }}-x_{\text {real }}\right|$ on minimum, even on the price of higher $\left|y_{\text {ideal }}-y_{\text {real }}\right|$ values, 3 . if we have only a few electrodes with wrong position, it is possible to ignore them, and to carry out the inversion without these data, 4 . it would be useful to eliminate this effect, taking into account the real position of the electrodes. Keeping all these things in mind, the reliability of the data will improve, even in case of high surface rockiness.

At the same time, as for the consequences on numerical modelling one should know the followings. 1. The consequences of the positioning errors on the pseudosection of apparent- and inverted resistivities depend very much on the array geometry (the increasing order of these effects is: $\mathrm{PP}, \mathrm{Wa}, \mathrm{PDP}, \mathrm{Wb}$, in agreement with the conclusion by Zhou and Dahlin 2003). 2. The error propagates systematically and not randomly (in opposite to the common geoelectric assumptions). Consequently in the inverted resistivity images the size of the false anomalies can be large.

In the light of our conclusions it would be especially important to investigate in details, if the assumption of numerical modelling about a random error is at all realistic. 


\section{Acknowledgements}

Hungarian Scientific Research Fund (projects K049604 and NI61013). Sándor Szalai is a grantee of Bolyai Research Scholarship of the Hungarian Academy of Sciences.

\section{References}

Athanasiou E N, Tsourlos P I, Papazachos C B, Tsokas G N 2007: J. Appl. Geoph., 62, 124-140.

Loke M H, Barker R D 1995: Geophysics, 60, 1682-1690.

Zhou B, Dahlin T 2003: Near Surface Geophysics, Vol. 1(3), 105-117.

Acta Geod. Geoph. Hung. 43, 2008 